OPEN ACCESS

Edited by:

Jennifer Brown,

Dana-Farber Cancer Institute,

United States

Reviewed by:

Mepur Hanumantha-Rao

Ravindranath,

Children's Hospital of Los Angeles, United States

Tingting Zhang,

Seattle Children's Research Institute, United States

*Correspondence:

Marzia Palma

Marzia.Palma@ki.se

Specialty section:

This article was submitted to

B Cell Biology,

a section of the journal

Frontiers in Immunology

Received: 27 March 2021 Accepted: 16 June 2021

Published: 01 July 2021

Citation:

Palma M, Mulder TA and Österborg A (2021) BTK Inhibitors in Chronic

Lymphocytic Leukemia: Biological Activity and Immune Effects.

Front. Immunol. 12:686768. doi: 10.3389/fimmu.2021.686768

\section{BTK Inhibitors in Chronic Lymphocytic Leukemia: Biological Activity and Immune Effects}

\author{
Marzia Palma ${ }^{1,2^{*}}$, Tom A. Mulder ${ }^{1}$ and Anders Österborg ${ }^{1,2}$ \\ 1 Department of Oncology-Pathology, Karolinska Institutet, Stockholm, Sweden, 2 Department of Hematology, Karolinska \\ University Hospital, Stockholm, Sweden
}

Bruton's tyrosine kinase (BTK) inhibitor (BTKi)s block the B-cell receptor (BCR) signaling cascade by binding to the BTK enzyme preventing the proliferation and survival of malignant and normal B cells. During the past decade, the clinical use of BTKis for the treatment of B-cell malignancies has exponentially grown, changing the treatment landscape for chronic lymphocytic leukemia (CLL) in particular. At present, three different covalent BTKis, ibrutinib, acalabrutinib and zanubrutinib, are FDA-approved and many new inhibitors are under development. Despite having remarkable selectivity for BTK, the first-in-class BTKi ibrutinib can also bind, with various affinities, to other kinases. The combined inhibition of BTK ("on-target" effect) and other kinases ("off-target" effect) can have additive or synergistic anti-tumor effects but also induce undesired side effects which might be treatment-limiting. Such "off-target" effects are expected to be more limited for second-generation BTKis. Moreover, the blockade of BCR signaling also indirectly affects the tumor microenvironment in CLL. Treatment with BTKis potentially impacts on both innate and adaptive immunity. Whether this affects infection susceptibility and vaccination efficacy requires further investigation. Here, we summarize the available knowledge on the impact of BTKis on the immune system and discuss the possible clinical implications. Indeed, a deeper knowledge on this topic could guide clinicians in the management and prevention of infections in patients with CLL treated with BTKis.

Keywords: BTK inhibitors, ibrutinib, leukemia, off-target effects, immune cells, infections, vaccination

\section{INTRODUCTION}

Chronic lymphocytic leukemia (CLL) is characterized by the accumulation of mature monoclonal $\mathrm{CD}^{+} \mathrm{B}$ lymphocytes in the secondary lymphoid organs, bone marrow and peripheral blood. Signaling through the B-cell receptor (BCR) is central in CLL and Bruton's tyrosine kinase (BTK) is a vital component of the BCR signaling pathway (1). BTK inhibitor (BTKi)s block the BCR signaling cascade by binding to the BTK enzyme, hence preventing the proliferation and survival of malignant and normal B cells. Indeed, BTK is essential for the activation of pathways which promote lymphocyte survival, such as the nuclear factor kappaB (NF- $\mathrm{kb}$ ) pathway (2), and regulates chemokine secretion and B-cell adhesion by activation of phospholipase $\mathrm{C} \gamma 2$ (PLC $\gamma 2)$ (3). 
The first-in-class BTKi ibrutinib, which inactivates BTK by binding covalently to cysteine 481 in the ATP-binding site of the enzyme in an irreversible manner, is FDA-approved for the treatment of CLL, mantle cell lymphoma (MCL), Waldenström's macroglobulinemia, marginal zone lymphoma, and graft-versushost disease. At present, two additional covalent BTKis, acalabrutinib and zanubrutinib, are FDA-approved for the treatment of MCL and CLL. Many new inhibitors, which bind reversibly, non-covalently, to the BTK are under development. The structure-function relationships of covalent and noncovalent BTKis are discussed by Zain et al. in the same issue of this journal.

In the past years, BTKis have been increasingly used for the treatment of B-cell malignancies, significantly changing the treatment algorithm for CLL in particular.

Despite having remarkable selectivity for BTK, ibrutinib can bind to other kinases with various affinities. Among these, interleukin-2-inducible T-cell kinase (ITK), which is highly expressed in $\mathrm{T}$ cells, and three epidermal growth factor receptor (EGFR) family kinases: EGFR, ErbB2/HER2 and ErbB4/HER4. The combined inhibition of BTK ("on-target" effect) and other kinases ("off-target" effect) can have additive or synergistic anti-tumor effects but also induce undesired side effects, such as atrial fibrillation (AF) and bleeding.

The two second-generation BTKis, acalabrutinib and zanubrutinib, were designed to more selectively bind to cysteine 481 in the kinase domain and therefore have less "offtarget" effects than ibrutinib. Phase 3 clinical trials are ongoing to compare the efficacy and toxicity profile of acalabrutinib and zanubrutinib with ibrutinib in CLL.

Besides "on-target" and "off-target" activity, there is, at least in CLL, convincing evidence that the anti-tumor effect of ibrutinib is related to the indirect effect that the blockade of the BCR-signaling has on the tumor microenvironment (TME) (4). In CLL, the TME is supporting the tumor cell survival and growth by various mechanisms including triggering of BCR signaling and immune anergy, which leads to immune deficiency and susceptibility to infections. Treatment with BTKis potentially impacts on both innate and adaptive immunity, but to what extent this affects infection susceptibility in patients with CLL is still under investigation.

Here, we summarize the available knowledge on the biological activity of BTKis on immune cells, trying to dissect which of the effects can be attributed to BTK-inhibition itself ("on-target" activity), which indirectly result from BTK-inhibition suppressing the cross-talk within the TME ("on/off-target"), and which are truly due to the inhibition of kinases other than BTK ("off-target").

\section{ANTI-TUMOR EFFECTS OF BTK INHIBITORS IN CLL}

The active occupancy of the ATP-binding site of BTK by BTKis inhibits the subsequent phosphorylation of BTK, PLC $\gamma 2$, AKT and ERK abolishing the BCR signaling downstream of BTK both in vitro and in vivo. In CLL, the BCR signaling pathway is constitutively activated, in immunoglobulin heavy-chain variable (IGHV) mutated cases in particular (5), and the anti-tumor effect of BTKis firstly depends on the direct inhibition of BTK (6). Indeed, after inhibition of the BTK, pathways involved in CLL cells survival and expansion, such as the NF-Kb pathway (7) as well as BAFF-R signaling (8), cannot be activated. Chemokine secretion, specifically CCL3 and CCL4, and adhesion of B cells, is also inhibited (9). The degree of BTK inhibition is traditionally measured by assessment of target occupancy, which has been evaluated in phase 1 studies. Available data suggest that sustained target occupancy during acalabrutinib treatment is necessary for the down-regulation of pathogenic pathways and to slow down BTK re-synthesis in CLL patients (10). However, whether the degree of BTK occupancy impacts on the clinical outcome is still unknown.

Ibrutinib, the pioneer of BTKis, exhibits remarkable selectivity for BTK. However, its anti-tumor effect likely also depends on the indirect effect that the blockade of the BCR-signaling has on the TME ("on/off-target"). Indeed, the TME in CLL plays a major role in sustaining tumor cell survival and growth in the bone marrow and/or lymphoid tissues (11). This is further supported by the limited direct pro-apoptotic activity observed when purified CLL cells are incubated in vitro with ibrutinib (12), while apoptosis can be induced through mobilization of the leukemic cells from the lymph nodes in vivo $(7,13)$. Upregulation of the survival protein $\mathrm{Bcl}-2$, can be induced, as an example, by $\mathrm{T}$ cells through soluble factors such as IL-4 and IFN- $\gamma(14,15)$, or directly through CD40CD40L interaction (16), which is a key proliferative signal for CLL cells. Recently, it was shown that miRNAs can actively participate in the crosstalk between CLL cells and T cell signals and facilitate the co-occurrence of BCR and CD40 signaling activation (17).

Chemokine receptors and adhesion molecules expressed on CLL cells are involved in the CLL-cell homing to the lymphoid organs. As an example, the CXCR4 chemokine receptor is highly expressed on the surface of CLL cells in the peripheral blood and mediates CLL cells chemotaxis and migration in response to CXCR4 ligand stromal cell-derived factor 1 (SDF-1 $\alpha$, CXCL12) produced by NLC. BCR engagement on CLL cells induces increased expression of these molecules (9) and it is therefore not surprising that BTK-inhibition by ibrutinib affects tumor cells-TME cells interactions, e.g. impairing CXCR4 signaling and therefore inhibiting cellular adhesion $(18,19)$. Indeed, shortly after start of ibrutinib treatment, a temporary increase in the absolute lymphocyte count, so-called "redistribution lymphocytosis", is observed in patients with CLL $(13,20)$, reflecting the release of tumor cells from the lymphoid organs to the peripheral blood (4). The downregulation of the CXCR4/CXCL12 axis also leads to the downregulation of both $\mathrm{CD} 20$ and of the anti-apoptotic protein Mcl1 in vivo (21).

Finally, nine other kinases which have a corresponding cysteine residue in the ATP-binding site as BTK, are also likely affected by ibrutinib. These include four TFK members (ITK, TEC, BMX and RLK/TXK), three EGFR family kinases (EGFR, ErbB2/HER2 and ErbB4/HER4) and two other kinases, BLK and JAK3. The inhibition of these other kinases ("off-target" effect) can contribute to ibrutinib's anti-tumor activity but also induce side effects which might be treatment-limiting. 
Historically, the treatment of choice for CLL has been chemoimmunotherapy but the prognosis for high-risk patients, i.e. with relapsed/refractory $(\mathrm{R} / \mathrm{R})$ or del17p/TP53-mutated disease has been poor (22). However, during the last decade targeted therapies including BTKis, B-cell lymphoma 2 (BCL2) antagonists and phosphoinositide 3-kinase (PI3K) inhibitors entered the therapeutic scene and significantly improved the overall outcome for patients with TP53 aberration and advanced-phase CLL (23-25).

Ibrutinib is now a cornerstone in high-risk patients (23) and often recommended as first-line treatment particularly in IGHV unmutated cases in the US (26-28). Overall response rates generally exceed $80 \%$ in trials and outside in both treatment-naïve and R/R patients but complete response rates are less than $10 \%(23,27,29$, $30)$. Treatment duration is indefinite, i.e. the patients stay on treatment until disease progression or unacceptable toxicity occurs. This latter, most commonly including AF, infections, pneumonitis, bleeding and diarrhea, led to treatment discontinuation in approximately $10 \%$ of the patients in clinical trials (31).

\section{IMMUNOMODULATORY EFFECTS OF BTK INHIBITORS}

Beyond its role in the development and functioning of B cells, BTK seems also to play a key role in innate immunity, being expressed in myeloid and other innate immune cells and regulating a number of immunological signaling networks within cells of the innate immune system (32). Moreover, as mentioned above, the selectivity for BTK of ibrutinib in particular is far from being absolute, which can result in "off-target" effects on immune cells of both the innate and the adaptive immune system. Therefore, the immunomodulatory effects of BTKis can depend both on "ontarget" on immune cells other than B cells and "off-target" effects.

\section{Effect on Innate Immunity}

Ibrutinib seems to hamper the cytotoxic activity of NK cells (33), while zanubrutinib does not seem to impair NK cell function to the same extent. This is most likely due to the inhibition of ITK by ibrutinib, which is much weaker with zanubrutinib, as demonstrated in patients with MCL (34). ITK also mediates downstream signaling of the Fc receptor (FcR) (35), which might explain why ibrutinib reduced antibody-dependent cellular cytotoxicity (ADCC) by NK cells (36).

BTK is important for the development of neutrophils (37) and mediates signaling through Toll-like receptors and the FcR as well as activation of the NLRP3-inflammasome in macrophages (32, 38-40) and DC (41, 42).

As the most potent antigen-presenting cells (APC), DC play a crucial role in bridging innate and adaptive immunity, thereby facilitating immunological memory, which is the cornerstone of vaccination. Hepatocyte growth factor (HGF) and T cell Ig and mucin protein-3 (TIM-3)-mediated BTK activity can suppress the NF- $\mathrm{KB}$ pathway in DC, which inhibits their activation and maturation $(43,44)$. On the other hand, ibrutinib-treated DC have been shown to promote $\mathrm{T}$-cell proliferation and drive a Th17 response (45).
It has also been demonstrated that both ibrutinib and acalabrutinib reduce the phagocytosis and secretion of inflammatory cytokines by monocytes and macrophages in response to fungal stimuli $(46,47)$, which could contribute to the susceptibility to invasive fungal infections (aspergillosis among others) observed in patients treated with ibrutinib (48-50). Furthermore, ibrutinib seems to reduce the expression of chemotactic factors that tumor-infiltrating macrophages (TAM), or nurse-like cells (NLC) in CLL, use to attract and protect CLL cells (51). Myeloid-derived suppressor cells (MDSC), another type of tumor-promoting myeloid cells, express BTK and it has been shown that ibrutinib blocks their development and immunosuppressive function (52). It has been observed that the expression of PD-L1 on MDSC decreases during zanubrutinib treatment (53).

Mast cells express BTK and other TEC family kinases (54). BTK, ITK and TEC are important for the degranulation and cytokine production of mast cells upon FcR stimulation in mice $(55,56)$ and ibrutinib has also been shown to reduce these functions in human cells (38). Although basophils and eosinophils are not so abundant, they play a significant role in the immune response against infections. The effect that BTKi might have on these cells deserves therefore to be studied more thoroughly.

Natural Killer T (NKT) cells and $\gamma \delta$ T cells combine features that are characteristic for innate and adaptive immunity. Innate lymphoid cells (ILC) are primarily tissue resident innate immune cells that descend from common lymphoid progenitors. Ibrutinib seems to hamper degranulation of $\gamma \delta \mathrm{T}$ cells (57). Even if relatively scarce, these cell types are important in the early response against pathogens. Whether they are influenced by BTKis is a largely uncharted territory of research.

\section{Effects on Adaptive Immunity}

Hypogammaglobulinemia is frequently observed in patients with CLL, with varying prevalence $(20-70 \%)$ in different reports, and is more evident in progressive disease. Its severity correlates with infection risk (58), thus justifying immunoglobulin (Ig) replacement therapy. The etiology of hypogammaglobulinemia is not elucidated, but likely due to a perturbation of the $\mathrm{T}$ cell/B cell interaction induced by the cancer cells (59).

In the study by Sun et al., normal B cells seemed to increase over time during ibrutinib treatment, more significantly in treatment-naive patients compared to $\mathrm{R} / \mathrm{R}$ ones. However, B-cell numbers remained abnormally low compared to healthy individuals. Despite the fact that BTK-deficiency in patients with X-linked agammaglobulinemia (XLA) leads to loss of circulating mature B cells and serum Igs, no significant decrease in IgG levels has been reported in patients during the first 6 months of ibrutinib treatment, while it became evident after 12 months (60). However, an increase of IgA levels over time has been reported by different studies $(20,29,60)$, so at least a partial reconstitution of humoral immunity seems to occur.

Abnormal T-cell subset distribution and function is known in CLL, partly correlating with tumor burden and previous anticancer treatment (61). Skewing of the T-cell repertoire seems to occur early in the course of the disease, which has suggested that a positive selection of tumor-specific T-cell clones occurs (62).

The effects of ibrutinib on the T-cell compartment have been reviewed by Mhibik et al. (63). Even if the findings regarding the 
changes in T-cell numbers, including major subsets, during ibrutinib treatment have been controversial, with both reports on decrease $(64,65)$ and increase $(66)$, the available evidence seems to point out that $\mathrm{T}$ cells decrease in parallel with the reduction of the tumor burden $(64,65,67)$. Indeed, $\mathrm{T}$ cells are usually abnormally elevated in R/R CLL patients (61), chronically activated by tumor antigens. This might explain why $\mathrm{T}$ cells initially remain stable or increase during the first weeks of treatment when persistent lymphocytosis is observed, and then decrease later. However, no decrease in $\mathrm{CD}^{+}$and $\mathrm{CD}^{+}$T-cell numbers was seen after treatment with either acalabrutinib $(66,68)$ or zanubrutinib $(53)$.

Proliferating $\mathrm{T}$ cells and expression of activation markers and immune checkpoints (PD-1, CTLA-4) also decreased both after treatment with ibrutinib $(64,65,69)$, acalabrutinib (68) and zanubrutinib (53), also likely reflecting the decrease in tumor burden.

With regard to the T-cell receptor (TCR) diversity, discordant findings have been reported. In one study, an increase in TCR diversity was reported after 12 months of treatment ibrutinib with or without rituximab in patients with $\mathrm{R} / \mathrm{R} \mathrm{CLL}$, positively correlating with clinical response and lower infection rates (67), while in another a more clonal repertoire was noted in patients responding to ibrutinib (70).

In T cells, ITK is highly expressed and blocked by ibrutinib in a BTK-independent manner (71). ITK plays a central role in Tcell maturation and differentiation into type 2 T-helper (Th2) effector cells. It has been shown that differentiation and migration of $\mathrm{T}$ cells to the lungs is compromised in ITKknockout mice (72). By blocking ITK, ibrutinib has the potential to selectively decrease Th2 cell numbers causing Th1 skewing (69). Indeed, several studies have reported the reduction of some Th2-cytokines in ibrutinib-treated patients $(64,66,67$, 73). However, no change in Th1/Th2 polarization was observed in patients treated with acalabrutinib (66) or zanubrutinib (53), supporting the idea that ITK inhibition is central in Th skewing. Moreover, a decrease in Th17 cells and related cytokines was also observed $(64,67)$, as well as in the numbers of regulatory $\mathrm{T}$ cells (Tregs) in the first weeks of treatment (73), which is also supposed to be mediated by ITK inhibition. An increase in Th17 cells number was also observed in $\mathrm{R} / \mathrm{R}$ patients treated with both acalabrutinib (66) and zanubrutinib (53). The immunomodulatory effects of BTKis are summarized in Table $\mathbf{1 .}$

\section{IMPACT OF BTK INHIBITORS ON INFECTION SUSCEPTIBILITY}

In patients with CLL, recurrent infections are a major cause of morbidity and mortality. The high infection rate is due a number of immune defects inherent to the disease, consisting of

TABLE 1 | Immunomodulatory effects of BTK inhibitors.

Cell type Biological function

Impact of BTKi on cell number/function (mediated by)

ibrutinib acalabrutinib zanubrutinib

\begin{tabular}{|c|c|c|c|c|}
\hline \multicolumn{5}{|c|}{ ADAPTIVE IMMUNE SYSTEM } \\
\hline \multicolumn{5}{|l|}{ T cells } \\
\hline $\mathrm{CD}^{+}$ & anti-tumor cytotoxic activity & decrease & no change & no change \\
\hline $\mathrm{CD}^{+}$ & helper function in Ag-presentation & decrease & no change & no change \\
\hline Th1 & anti-tumor immune response & increase (RLK)? & no change & no change \\
\hline Th2 & impairment of anti-tumor immune response & decrease (ITK) & no change & no change \\
\hline Th17 & immunosuppression/immune evasion & decrease (ITK) & no change & decrease (?) \\
\hline Tregs & immunosuppression & decrease (ITK) & N/A & N/A \\
\hline \multirow[t]{2}{*}{ B cells } & IgA production & increase & $\mathrm{N} / \mathrm{A}$ & N/A \\
\hline & IgG production & decrease & $\mathrm{N} / \mathrm{A}$ & $\mathrm{N} / \mathrm{A}$ \\
\hline \multicolumn{5}{|c|}{ INNATE IMMUNE SYSTEM } \\
\hline \multirow[t]{2}{*}{ NK } & Cytotoxic activity & decrease (ITK) & $\mathrm{N} / \mathrm{A}$ & $\mathrm{N} / \mathrm{A}$ \\
\hline & ADCC & decrease (ITK-mediated signaling of the FcR) & $\mathrm{N} / \mathrm{A}$ & $\mathrm{N} / \mathrm{A}$ \\
\hline Phagocytes & engulf and digest pathogens & N/A & $\mathrm{N} / \mathrm{A}$ & N/A \\
\hline Neutrophils & degranulate antimicrobial factors & decrease (BTK; TEC)? & $\mathrm{N} / \mathrm{A}$ & $\mathrm{N} / \mathrm{A}$ \\
\hline \multirow[t]{2}{*}{$\begin{array}{l}\text { Monocytes/ } \\
\text { Macrophages/DC }\end{array}$} & Ag presentation & $\begin{array}{l}\text { decrease (BTK via TLR, FCR and NLRP3- } \\
\text { inflammasome). TEC? }\end{array}$ & $\mathrm{N} / \mathrm{A}$ & $\mathrm{N} / \mathrm{A}$ \\
\hline & $\begin{array}{l}\text { phagocytosis and secretion of inflammatory cytokines in } \\
\text { response to fungal stimuli }\end{array}$ & decrease (BTK) & decrease & $\mathrm{N} / \mathrm{A}$ \\
\hline TAM (nurse-like cells) & expression of chemotactic factors for CLL cells & decrease & $\mathrm{N} / \mathrm{A}$ & N/A \\
\hline MDSC & Tumor-promotion, immunosuppression & decrease (BTK) & $\mathrm{N} / \mathrm{A}$ & decrease (BTK) \\
\hline Mast cells & $\begin{array}{l}\text { degranulation and cytokine production in response allergens } \\
\text { and parasites }\end{array}$ & decrease (BTK, ITK, TEC) & $\mathrm{N} / \mathrm{A}$ & $\mathrm{N} / \mathrm{A}$ \\
\hline basophils & & $\mathrm{N} / \mathrm{A}$ & $\mathrm{N} / \mathrm{A}$ & N/A \\
\hline eosinophils & & $\mathrm{N} / \mathrm{A}$ & $\mathrm{N} / \mathrm{A}$ & $\mathrm{N} / \mathrm{A}$ \\
\hline NKT & early response & $\mathrm{N} / \mathrm{A}$ & $\mathrm{N} / \mathrm{A}$ & $\mathrm{N} / \mathrm{A}$ \\
\hline$\gamma \delta$ T cells & degranulation & decrease & N/A & $\mathrm{N} / \mathrm{A}$ \\
\hline
\end{tabular}

Ag, antigen; Th1, type 1 T-helper; Th2, type 2 T-helper; Tregs, regulatory T cells; Ig, immunoglobulin; NK, natural killer; ADCC, antibody-dependent cellular cytotoxicity; FCR, FC receptor; DC, dendritic cells; Ag, antigen; TLR, Toll-like receptors; TAM, tumor-associated macrophages; MDSC, myeloid-derived suppressor cells; NKT, Natural Killer T; N/A, not assessed. 
hypogammaglobulinemia, abnormal T-cell function and neutropenia due to bone marrow infiltration, and further aggravated by cytopenias induced by CLL treatment (59). Hence, the risk of infectious complications increases with disease progression and the spectrum of the pathogens also expands, including, in addition to encapsulated bacteria mostly seen in patients with early, untreated CLL, more opportunistic agents such as Pneumocystis jirovecii and mycobacteria in the advanced disease setting (74).

Despite the high overall response rate and disease control achieved with ibrutinib, infections are not absent during longterm treatment with ibrutinib. By a systematic review of prospective trials with ibrutinib for the treatment of lymphoid malignancies, it was found that $56 \%$ patients treated with singleagent ibrutinib experienced an infectious complication of any grade. Grade 3-4 infectious adverse events occurred in $26 \%$ of the patients; of these, $13 \%$ were pneumonia (75). Of notice, the incidence of fungal opportunistic infections was in the range of 3 to $6 \%$ in reported series of patients with lymphoid malignancies, mainly CLL (76-78).

In patients with CLL during treatment with ibrutinib, most commonly respiratory tract infections, gastrointestinal/genitourinary and skin infections are observed (60). Higher infection rates have been reported in $\mathrm{R} / \mathrm{R}$ patients, with infections $\geq$ grade 3 reported in more than $30 \%$ of the patients $(20,23)$ compared to $10-20 \%$ in those previously untreated $(29,30,79)$. However, the incidence of infections seems to be highest during the first months of treatment to decrease over time $(20,60,79)$.

In the study by Sun et al., the infection rate was significantly higher during the first 6 months of ibrutinib treatment, especially in previously treated patients compared to those receiving ibrutinib as first-line. As discussed above, in this study, despite normal B cells apparently increasing over time, IgG levels decreased, but IgA increased and a significant correlation was observed between increase in IgA levels at 12 months of treatment and infection rate, independent of previous treatment history (60).

Whether increased infection susceptibility is a class-effect or there are any differences between the different BTKis remains to be elucidated. Since it likely depends on the effect on different pathways and not only on BTK inhibition, it could be speculated that treatment with more selective BTKis, such as acalabrutinib, not affecting the ITK, could result in lower infection rates. However, in the largest phase 3 acalabrutinib trial in the $R / R$ setting, grade $\geq 3$ infectious complications occurred in $23 \%$ of the patients (68). Table 2 summarizes in a simplified way how the effect of BTKi treatment on the different immune cell types can potentially affect susceptibility to different kinds of pathogens.

\section{EFFECT OF BTKI ON VACCINATION EFFICACY}

Suboptimal response to vaccination has been reported in patients with CLL, even in those with indolent and previously untreated disease (80). In general, seroconversion in CLL patients negatively correlates with previous treatment. Following treatment with antiCD20 monoclonal antibodies, the serological response to H1N1influenza vaccination was absent for at least 6 months following exposure, recovering 12 months after (81).

Even if not all Ig subclasses seem to decrease in CLL patients during treatment with ibrutinib $(20,60)$, probably reflecting the persistence of long-lived plasma cells generated in response to

TABLE 2 | Potential impact of treatment with BTK inhibitors on infectious susceptibility.

\begin{tabular}{|c|c|c|c|c|c|}
\hline Cell type & Biological function & $\begin{array}{l}\text { BTKi impact on } \\
\text { cell } \\
\text { number/function }\end{array}$ & $\begin{array}{l}\text { On-target } \\
\text { effect }\end{array}$ & $\begin{array}{l}\text { Off-target } \\
\text { effect }\end{array}$ & $\begin{array}{l}\text { Potentially increased risk } \\
\text { of infection by }\end{array}$ \\
\hline \multicolumn{6}{|c|}{ ADAPTIVE IMMUNE SYSTEM } \\
\hline \multicolumn{6}{|l|}{ T cells } \\
\hline $\mathrm{CD}^{+}$ & cytotoxic activity & decrease & & $x$ & virus, bacteria \\
\hline $\mathrm{CD}^{+}$ & $\begin{array}{l}\text { helper function in } \\
\text { Ag presentation }\end{array}$ & decrease & & $x$ & virus, bacteria \\
\hline Th1 & promotion of cellular immunity & increase/decrease & & $x$ & intracellular pathogens \\
\hline Th2 & promotion of humoral immunity & decrease & & $x$ & $\begin{array}{l}\text { Extracellular pathogens, } \\
\text { parasites }\end{array}$ \\
\hline Th17 & $\begin{array}{l}\text { promotion of tissue inflammation, neutrophils } \\
\text { recrutiment }\end{array}$ & decrease & & $x$ & extracellular bacteria and fungi \\
\hline B cells & IgG production & & $x$ & & $\begin{array}{l}\text { bacteria, opportunistic } \\
\text { pathogens }\end{array}$ \\
\hline \multicolumn{6}{|c|}{ INNATE IMMUNE SYSTEM } \\
\hline NK & $\begin{array}{l}\text { Cytotoxic activity } \\
\text { ADCC }\end{array}$ & decrease & & $\begin{array}{l}x \\
x\end{array}$ & Viruses, intracellular bacteria \\
\hline Neutrophils & $\begin{array}{l}\text { Ag recognition } \\
\text { maturation } \\
\text { degranulation }\end{array}$ & decrease & $\begin{array}{l}x \\
x \\
x\end{array}$ & & Bacteria, fungi \\
\hline $\begin{array}{l}\text { Monocytes/ } \\
\text { Macrophages }\end{array}$ & $\begin{array}{l}\text { Ag presentation } \\
\text { phagocytosis and cytokine secretion }\end{array}$ & decrease & $\begin{array}{l}x \\
x\end{array}$ & $X(?)$ & Bacteria, fungi \\
\hline Mast cells & degranulation and cytokine production & decrease & $x$ & $x$ & parasites \\
\hline$\gamma \delta \mathrm{T}$ cells & degranulation & decrease & $?$ & $?$ & \\
\hline
\end{tabular}

Ag, antigen; Th1, type 1 T-helper; Th2, type 2 T-helper; Ig, immunoglobulin; NK, natural killer; ADCC, antibody-dependent cellular cytotoxicity; Ag, antigen. 
previous infections and vaccinations, it is assumable that longterm BTKi treatment might impair the ability to mount an effective immune response following vaccination, since B-cell maturation relies on functional BTK.

In two studies evaluating the seroconversion rate after seasonal influenza vaccine in patients treated with ibrutinib, this was found to be as low as $7 \%$ after standard dose (82) and $26 \%$ after higher dose (83).

Pleyer et al. recently reported on the outcome of vaccination with the adjuvanted recombinant hepatitis B (HepB-CpG) and zoster (RZV) vaccines in CLL patients treated with BTKi compared to untreated patients. While no difference was observed between the two patient groups with regard to the serological response to RZV vaccine (41\% vs 59\%), the de novo humoral response to the HepB-CpG vaccine was significantly lower in BTKi-treated patients (3.8\% vs 28\%) (84).

Another study (85) recently confirmed the immunological efficacy of vaccination with adjuvanted recombinant varicella zoster glycoprotein in CLL patients during front-line therapy for $\geq 3$ months with BTKi. Humoral and cellular responses were observed in $75 \%$ and $78 \%$ of the patients, respectively. However, lower cell-mediated immunogenicity to the same vaccine was recently reported in BTKi-treated CLL patients compared to patients with monoclonal B-cell lymphocytosis (MBL) or untreated CLL (37\% vs 73\%) (86).

In another study assessing antibody response to the 13-valent pneumococcal conjugate vaccine (PCV13) in 112 patients with CLL, of which 35 during ibrutinib treatment, immune responses were observed in only nine (8\%) patients, eight treatment-naïve and one on front-line ibrutinib. None of the patients vaccinated $\geq 6$ months after chemoimmunotherapy treatment with antiCD20 monoclonal antibodies developed an immune response (87). Similarly, no adequate immune response to PCV13 was observed in 4 previously treated patients receiving ibrutinib while it was seen in all 4 previously treated CLL control patients with no ongoing therapy (88).

\section{CONCLUSION AND PERSPECTIVES}

During the last decade, treatment with BTKis has significantly improved the prognosis of R/R CLL patients. More extended clinical applications are also awaited, e.g. in the setting of first-line treatment in combination with other biological drugs, such as Bcl-2 antagonists. However, it is now clear that treatment with BTKis broadly affects the adaptive and the innate immune system in patients with CLL. This could explain the relatively high incidence of certain types of infections, such as invasive fungal infections, observed in ibrutinib-treated patients $(48,49)$. Infections are higher in the first months of treatment and the incidence decreases with decreasing tumor burden. However, when studying infection susceptibility in CLL patients, many factors should be taken into consideration which make it difficult to compare data from different studies. Among these, biological features of the disease (low $v s$ high-risk) as well as previous and concomitant treatment including steroids, exposure to environmental risk factors, hypogammaglobulinemia with or without ongoing Ig substitution.
With regard to vaccination efficacy, the available data indicate that treatment with BTKi hampers the ability to mount a vaccineinduced immune response against novel antigens. Since T cells are also affected, at least by treatment with ibrutinib, it can be speculated that T-cell dependent B-cell activation is impaired twice, by BTK and ITK inhibition. This issue is of enormous relevance in the light of the ongoing COVID-19 pandemic, especially since patients with CLL may be at high risk of poor outcome if hospitalized due COVID-19 $(89,90)$. Further investigation is warranted, including studies on novel vaccination strategies, in patients with CLL. Indeed, it is presumable that patients in different disease phases and with different treatment histories (previous/ongoing) will not respond unanimously to vaccination, and that a patient-tailored vaccination approach might be needed, including temporary suspension of CLL treatment in patients in clinical remission to maximize vaccination efficacy.

Many new inhibitors, which bind reversibly, non-covalently, to the cysteine 481 of the BTK are under development. Indeed, due to safety concerns, irreversible inhibitors are regarded with caution as possible treatment for non-malignant diseases, such as autoimmune ones. Therefore, an alternative binding manner which would allow the compound to inactivate the BTK only temporarily, but with greater potency, is appealing. The expectations from these new compounds are also that they will not cause treatment-resistance due to BTK and/or PLC $\gamma 2$ mutations. However, "off-target" effects are expected to be more consistent, due to the potential binding to multiple structurally related kinases. The challenge is therefore to design reversible covalent binding compounds with more tuneable, on-target residence times (91) than those observed with irreversible inhibitors.

In conclusion, further studies are needed to characterize in depth the biological effects of BTKis to implement new applications of the existing inhibitors in other disease settings or in combination with other drugs, and to guide the development of new, more or less targeted, inhibitors. Moreover, a deeper knowledge of the impact of BTKis on the immune system could guide clinicians in the management of infections and in the prevention thereof.

\section{AUTHOR CONTRIBUTIONS}

MP and TM wrote the first version of the manuscript, AÖ edited the first version of the manuscript. All authors contributed to the article and approved the submitted version.

\section{FUNDING}

This work was supported by grants from The Swedish Cancer Society, Ref nr: 200726 PjF; The Cancer Society in Stockholm, Ref nr: 184203; The Cancer and Allergy Foundation, Ref nr: 258; Dr. Åke Olsson's Foundation for Haematology research, Dnr: 2018-0015.

\section{ACKNOWLEDGMENTS}

We thank Ms Leila Relander for excellent secretarial assistance. 


\section{REFERENCES}

1. Smith CI. From Identification of the BTK Kinase to Effective Management of Leukemia. Oncogene (2017) 36(15):2045-53. doi: 10.1038/onc.2016.343

2. Petro JB, Rahman SM, Ballard DW, Khan WN. Bruton's Tyrosine Kinase Is Required for Activation of IkappaB Kinase and Nuclear Factor kappaB in Response to B Cell Receptor Engagement. J Exp Med (2000) 191(10):1745-54. doi: 10.1084/jem.191.10.1745

3. Petro JB, Khan WN. Phospholipase C-Gamma 2 Couples Bruton's Tyrosine Kinase to the NF-kappaB Signaling Pathway in B Lymphocytes. J Biol Chem (2001) 276(3):1715-9. doi: 10.1074/jbc.M009137200

4. Chen SS, Chang BY, Chang S, Tong T, Ham S, Sherry B, et al. BTK Inhibition Results in Impaired CXCR4 Chemokine Receptor Surface Expression, Signaling and Function in Chronic Lymphocytic Leukemia. Leukemia (2016) 30(4):833-43. doi: 10.1038/leu.2015.316

5. Guarini A, Chiaretti S, Tavolaro S, Maggio R, Peragine N, Citarella F, et al. BCR Ligation Induced by IgM Stimulation Results in Gene Expression and Functional Changes Only in IgV H Unmutated Chronic Lymphocytic Leukemia (CLL) Cells. Blood (2008) 112(3):782-92. doi: 10.1182/blood2007-12-127688

6. Woyach JA, Bojnik E, Ruppert AS, Stefanovski MR, Goettl VM, Smucker KA, et al. Bruton's Tyrosine Kinase (BTK) Function is Important to the Development and Expansion of Chronic Lymphocytic Leukemia (CLL). Blood (2014) 123(8):1207-13. doi: 10.1182/blood-2013-07-515361

7. Herman SE, Mustafa RZ, Gyamfi JA, Pittaluga S, Chang S, Chang B, et al. Ibrutinib Inhibits BCR and NF-kappaB Signaling and Reduces Tumor Proliferation in Tissue-Resident Cells of Patients With CLL. Blood (2014) 123(21):3286-95. doi: 10.1182/blood-2014-02-548610

8. Nishio M, Endo T, Tsukada N, Ohata J, Kitada S, Reed JC, et al. Nurselike Cells Express BAFF and APRIL, Which can Promote Survival of Chronic Lymphocytic Leukemia Cells via a Paracrine Pathway Distinct From That of SDF-1alpha. Blood (2005) 106(3):1012-20. doi: 10.1182/blood-2004-03-0889

9. Burger JA. Nurture Versus Nature: The Microenvironment in Chronic Lymphocytic Leukemia. Hematol Am Soc Hematol Educ Program (2011) 2011:96-103. doi: 10.1182/asheducation-2011.1.96

10. Sun C, Nierman P, Kendall EK, Cheung J, Gulrajani M, Herman SEM, et al. Clinical and Biological Implications of Target Occupancy in CLL Treated With the BTK Inhibitor Acalabrutinib. Blood (2020) 136(1):93-105. doi: 10.1182/blood.2019003715

11. Herishanu Y, Perez-Galan P, Liu D, Biancotto A, Pittaluga S, Vire B, et al. The Lymph Node Microenvironment Promotes B-Cell Receptor Signaling, NFkappaB Activation, and Tumor Proliferation in Chronic Lymphocytic Leukemia. Blood (2011) 117(2):563-74. doi: 10.1182/blood-2010-05-284984

12. Amin NA, Balasubramanian S, Saiya-Cork K, Shedden K, Hu N, Malek SN. Cell-Intrinsic Determinants of Ibrutinib-Induced Apoptosis in Chronic Lymphocytic Leukemia. Clin Cancer Res (2017) 23(4):1049-59. doi: 10.1158/1078-0432.CCR-15-2921

13. Wodarz D, Garg N, Komarova NL, Benjamini O, Keating MJ, Wierda WG, et al. Kinetics of CLL Cells in Tissues and Blood During Therapy With the BTK Inhibitor Ibrutinib. Blood (2014) 123(26):4132-5. doi: 10.1182/blood2014-02-554220

14. Buschle M, Campana D, Carding SR, Richard C, Hoffbrand AV, Brenner MK. Interferon Gamma Inhibits Apoptotic Cell Death in B Cell Chronic Lymphocytic Leukemia. J Exp Med (1993) 177(1):213-8. doi: 10.1084/jem.177.1.213

15. Dancescu M, Rubio-Trujillo M, Biron G, Bron D, Delespesse G, Sarfati M. Interleukin 4 Protects Chronic Lymphocytic Leukemic B Cells From Death by Apoptosis and Upregulates Bcl-2 Expression. J Exp Med (1992) 176(5):131926. doi: 10.1084/jem.176.5.1319

16. Schattner EJ, Mascarenhas J, Reyfman I, Koshy M, Woo C, Friedman SM, et al. Chronic Lymphocytic Leukemia B Cells can Express CD40 Ligand and Demonstrate T-Cell Type Costimulatory Capacity. Blood (1998) 91(8):268997. doi: 10.1182/blood.V91.8.2689.2689_2689_2697

17. Sharma S, Pavlasova GM, Seda V, Cerna KA, Vojackova E, Filip D, et al. miR29 Modulates CD40 Signaling in Chronic Lymphocytic Leukemia by Targeting TRAF4: An Axis Affected by BCR Inhibitors. Blood (2021) 137 (18):2481-94. doi: 10.1182/blood.2020005627

18. Ponader S, Chen SS, Buggy JJ, Balakrishnan K, Gandhi V, Wierda WG, et al. The Bruton Tyrosine Kinase Inhibitor PCI-32765 Thwarts Chronic
Lymphocytic Leukemia Cell Survival and Tissue Homing In Vitro and In Vivo. Blood (2012) 119(5):1182-9. doi: 10.1182/blood-2011-10-386417

19. de Rooij MF, Kuil A, Geest CR, Eldering E, Chang BY, Buggy JJ, et al. The Clinically Active BTK Inhibitor PCI-32765 Targets B-Cell Receptor- and Chemokine-Controlled Adhesion and Migration in Chronic Lymphocytic Leukemia. Blood (2012) 119(11):2590-4. doi: 10.1182/blood-2011-11-390989

20. Byrd JC, Furman RR, Coutre SE, Flinn IW, Burger JA, Blum KA, et al. Targeting BTK With Ibrutinib in Relapsed Chronic Lymphocytic Leukemia. $N$ Engl J Med (2013) 369(1):32-42. doi: 10.1056/NEJMoa1215637

21. Pavlasova G, Borsky M, Seda V, Cerna K, Osickova J, Doubek M, et al. Ibrutinib Inhibits CD20 Upregulation on CLL B Cells Mediated by the CXCR4/SDF-1 Axis. Blood (2016) 128(12):1609-13. doi: 10.1182/blood2016-04-709519

22. Hallek M, Cheson BD, Catovsky D, Caligaris-Cappio F, Dighiero G, Dohner $\mathrm{H}$, et al. Guidelines for the Diagnosis and Treatment of Chronic Lymphocytic Leukemia: A Report From the International Workshop on Chronic Lymphocytic Leukemia Updating the National Cancer Institute-Working Group 1996 Guidelines. Blood (2008) 111(12):5446-56. doi: 10.1182/blood2007-06-093906

23. O’Brien S, Jones JA, Coutre SE, Mato AR, Hillmen P, Tam C, et al. Ibrutinib for Patients With Relapsed or Refractory Chronic Lymphocytic Leukaemia With 17p Deletion (RESONATE-17): A Phase 2, Open-Label, Multicentre Study. Lancet Oncol (2016) 17(10):1409-18. doi: 10.1016/S1470-2045(16)30212-1

24. Stilgenbauer S, Eichhorst B, Schetelig J, Coutre S, Seymour JF, Munir T, et al. Venetoclax in Relapsed or Refractory Chronic Lymphocytic Leukaemia With 17p Deletion: A Multicentre, Open-Label, Phase 2 Study. Lancet Oncol (2016) 17(6):768-78. doi: 10.1016/S1470-2045(16)30019-5

25. Furman RR, Sharman JP, Coutre SE, Cheson BD, Pagel JM, Hillmen P, et al. Idelalisib and Rituximab in Relapsed Chronic Lymphocytic Leukemia. N Engl J Med (2014) 370(11):997-1007. doi: 10.1056/NEJMoa1315226

26. National Cancer Institute. Chronic Lymphocytic Leukemia Treatment. Available at: https://www.cancer.gov/types/leukemia/hp/cll-treatment-pdq.

27. Burger JA, Tedeschi A, Barr PM, Robak T, Owen C, Ghia P, et al. Ibrutinib as Initial Therapy for Patients With Chronic Lymphocytic Leukemia. N Engl J Med (2015) 373(25):2425-37. doi: 10.1056/NEJMoa1509388

28. Woyach JA, Ruppert AS, Guinn D, Lehman A, Blachly JS, Lozanski A, et al. BTK (C481S)-Mediated Resistance to Ibrutinib in Chronic Lymphocytic Leukemia. J Clin Oncol (2017) 35(13):1437-43. doi: 10.1200/JCO.2016.70.2282

29. O'Brien S, Furman RR, Coutre SE, Sharman JP, Burger JA, Blum KA, et al. Ibrutinib as Initial Therapy for Elderly Patients With Chronic Lymphocytic Leukaemia or Small Lymphocytic Lymphoma: An Open-Label, Multicentre, Phase 1b/2 Trial. Lancet Oncol (2014) 15(1):48-58. doi: 10.1016/S1470-2045 (13)70513-8

30. Brown JR, Hillmen P, O’Brien S, Barrientos JC, Reddy NM, Coutre SE, et al. Extended Follow-Up and Impact of High-Risk Prognostic Factors From the Phase 3 RESONATE Study in Patients With Previously Treated CLL/SLL. Leukemia (2018) 32(1):83-91. doi: 10.1038/leu.2017.175

31. Maddocks KJ, Ruppert AS, Lozanski G, Heerema NA, Zhao W, Abruzzo L, et al. Etiology of Ibrutinib Therapy Discontinuation and Outcomes in Patients With Chronic Lymphocytic Leukemia. JAMA Oncol (2015) 1(1):80-7. doi: 10.1001/jamaoncol.2014.218

32. Weber ANR, Bittner Z, Liu X, Dang TM, Radsak MP, Brunner C. Bruton's Tyrosine Kinase: An Emerging Key Player in Innate Immunity. Front Immunol (2017) 8:1454. doi: 10.3389/fimmu.2017.01454

33. Bojarczuk K, Siernicka M, Dwojak M, Bobrowicz M, Pyrzynska B, Gaj P, et al. B-Cell Receptor Pathway Inhibitors Affect CD20 Levels and Impair Antitumor Activity of Anti-CD20 Monoclonal Antibodies. Leukemia (2014) 28(5):1163-7. doi: 10.1038/leu.2014.12

34. Flinsenberg TWH, Tromedjo CC, Hu N, Liu Y, Guo Y, Thia KYT, et al. Differential Effects of BTK Inhibitors Ibrutinib and Zanubrutinib on NK-Cell Effector Function in Patients With Mantle Cell Lymphoma. Haematologica (2020) 105(2):e76-9. doi: 10.3324/haematol.2019.220590

35. Khurana D, Arneson LN, Schoon RA, Dick CJ, Leibson PJ. Differential Regulation of Human NK Cell-Mediated Cytotoxicity by the Tyrosine Kinase Itk. J Immunol (2007) 178(6):3575-82. doi: 10.4049/jimmunol.178.6.3575

36. Kohrt HE, Sagiv-Barfi I, Rafiq S, Herman SE, Butchar JP, Cheney C, et al. Ibrutinib Antagonizes Rituximab-Dependent NK Cell-Mediated Cytotoxicity. Blood (2014) 123(12):1957-60. doi: 10.1182/blood-2014-01-547869 
37. Fiedler K, Sindrilaru A, Terszowski G, Kokai E, Feyerabend TB, Bullinger L, et al. Neutrophil Development and Function Critically Depend on Bruton Tyrosine Kinase in a Mouse Model of X-Linked Agammaglobulinemia. Blood (2011) 117(4):1329-39. doi: 10.1182/blood-2010-04-281170

38. Chang BY, Huang MM, Francesco M, Chen J, Sokolove J, Magadala P, et al. The Bruton Tyrosine Kinase Inhibitor PCI-32765 Ameliorates Autoimmune Arthritis by Inhibition of Multiple Effector Cells. Arthritis Res Ther (2011) 13 (4):R115. doi: 10.1186/ar3400

39. Ren L, Campbell A, Fang H, Gautam S, Elavazhagan S, Fatehchand K, et al. Analysis of the Effects of the Bruton's Tyrosine Kinase (Btk) Inhibitor Ibrutinib on Monocyte Fcgamma Receptor (FcgammaR) Function. J Biol Chem (2016) 291(6):3043-52. doi: 10.1074/jbc.M115.687251

40. Ye B, Zhou C, Guo H, Zheng M. Effects of BTK Signalling in Pathogenic Microorganism Infections. J Cell Mol Med (2019) 23(10):6522-9. doi: 10.1111/ jcmm.14548

41. Taneichi H, Kanegane H, Sira MM, Futatani T, Agematsu K, Sako M, et al. Toll-Like Receptor Signaling is Impaired in Dendritic Cells From Patients With X-Linked Agammaglobulinemia. Clin Immunol (2008) 126(2):148-54. doi: 10.1016/j.clim.2007.10.005

42. Lougaris V, Baronio M, Vitali M, Tampella G, Cattalini M, Tassone L, et al. Bruton Tyrosine Kinase Mediates TLR9-Dependent Human Dendritic Cell Activation. J Allergy Clin Immunol (2014) 133(6):1644-50.e4. doi: 10.1016/ j.jaci.2013.12.1085

43. Singhal E, Kumar P, Sen P. A Novel Role for Bruton's Tyrosine Kinase in Hepatocyte Growth Factor-Mediated Immunoregulation of Dendritic Cells. J Biol Chem (2011) 286(37):32054-63. doi: 10.1074/jbc.M111.271247

44. Maurya N, Gujar R, Gupta M, Yadav V, Verma S, Sen P. Immunoregulation of Dendritic Cells by the Receptor T Cell Ig and Mucin Protein-3 via Bruton's Tyrosine Kinase and C-Src. J Immunol (2014) 193(7):3417-25. doi: 10.4049/ jimmunol.1400395

45. Natarajan G, Terrazas C, Oghumu S, Varikuti S, Dubovsky JA, Byrd JC, et al. Ibrutinib Enhances IL-17 Response by Modulating the Function of Bone Marrow Derived Dendritic Cells. Oncoimmunology (2016) 5(1):e1057385. doi: 10.1080/2162402X.2015.1057385

46. Bercusson A, Colley T, Shah A, Warris A, Armstrong-James D. Ibrutinib Blocks Btk-Dependent NF-kB and NFAT Responses in Human Macrophages During Aspergillus Fumigatus Phagocytosis. Blood (2018) 132(18):1985-8. doi: 10.1182/blood-2017-12-823393

47. Fiorcari S, Maffei R, Vallerini D, Scarfo L, Barozzi P, Maccaferri M, et al. BTK Inhibition Impairs the Innate Response Against Fungal Infection in Patients With Chronic Lymphocytic Leukemia. Front Immunol (2020) 11:2158. doi: 10.3389/fimmu.2020.02158

48. Ghez D, Calleja A, Protin C, Baron M, Ledoux MP, Damaj G, et al. EarlyOnset Invasive Aspergillosis and Other Fungal Infections in Patients Treated With Ibrutinib. Blood (2018) 131(17):1955-9. doi: 10.1182/blood-2017-11818286

49. Ruchlemer R, Ben-Ami R, Bar-Meir M, Brown JR, Malphettes M, Mous R, et al. Ibrutinib-Associated Invasive Fungal Diseases in Patients With Chronic Lymphocytic Leukaemia and non-Hodgkin Lymphoma: An Observational Study. Mycoses (2019) 62(12):1140-7. doi: 10.1111/myc.13001

50. Maffei R, Maccaferri M, Arletti L, Fiorcari S, Benatti S, Potenza L, et al. Immunomodulatory Effect of Ibrutinib: Reducing the Barrier Against Fungal Infections. Blood Rev (2020) 40:100635. doi: 10.1016/j.blre.2019.100635

51. Ping L, Ding N, Shi Y, Feng L, Li J, Liu Y, et al. The Bruton's Tyrosine Kinase Inhibitor Ibrutinib Exerts Immunomodulatory Effects Through Regulation of Tumor-Infiltrating Macrophages. Oncotarget (2017) 8(24):39218-29. doi: 10.18632/oncotarget.16836

52. Stiff A, Trikha P, Wesolowski R, Kendra K, Hsu V, Uppati S, et al. MyeloidDerived Suppressor Cells Express Bruton's Tyrosine Kinase and Can Be Depleted in Tumor-Bearing Hosts by Ibrutinib Treatment. Cancer Res (2016) 76(8):2125-36. doi: 10.1158/0008-5472.CAN-15-1490

53. Zou YX, Zhu HY, Li XT, Xia Y, Miao KR, Zhao SS, et al. The Impacts of Zanubrutinib on Immune Cells in Patients With Chronic Lymphocytic Leukemia/Small Lymphocytic Lymphoma. Hematol Oncol (2019) 37 (4):392-400. doi: 10.1002/hon.2667

54. Schmidt U, Boucheron N, Unger B, Ellmeier W. The Role of Tec Family Kinases in Myeloid Cells. Int Arch Allergy Immunol (2004) 134(1):65-78. doi: $10.1159 / 000078339$
55. Schmidt U, Abramova A, Boucheron N, Eckelhart E, Schebesta A, Bilic I, et al. The Protein Tyrosine Kinase Tec Regulates Mast Cell Function. Eur J Immunol (2009) 39(11):3228-38. doi: 10.1002/eji.200838839

56. Iyer AS, Morales JL, Huang W, Ojo F, Ning G, Wills E, et al. Absence of Tec Family Kinases Interleukin-2 Inducible T Cell Kinase (Itk) and Bruton's Tyrosine Kinase (Btk) Severely Impairs Fc epsilonRI-Dependent Mast Cell Responses. J Biol Chem (2011) 286(11):9503-13. doi: 10.1074/jbc.M110.165613

57. Risnik D, Elias EE, Keitelman I, Colado A, Podaza E, Cordini G, et al. The Effect of Ibrutinib on Neutrophil and Gammadelta T Cell Functions. Leuk Lymphoma (2020) 61(10):2409-18. doi: 10.1080/10428194.2020.1753043

58. Morrison VA. Infectious Complications in Patients With Chronic Lymphocytic Leukemia: Pathogenesis, Spectrum of Infection, and Approaches to Prophylaxis. Clin Lymphoma Myeloma (2009) 9(5):365-70. doi: 10.3816/CLM.2009.n.071

59. Ravandi F, O’Brien S. Immune Defects in Patients With Chronic Lymphocytic Leukemia. Cancer Immunol Immunother (2006) 55(2):197-209. doi: 10.1007/ s00262-005-0015-8

60. Sun C, Tian X, Lee YS, Gunti S, Lipsky A, Herman SE, et al. Partial Reconstitution of Humoral Immunity and Fewer Infections in Patients With Chronic Lymphocytic Leukemia Treated With Ibrutinib. Blood (2015) 126(19):2213-9. doi: 10.1182/blood-2015-04-639203

61. Palma M, Gentilcore G, Heimersson K, Mozaffari F, Nasman-Glaser B, Young E, et al. T Cells in Chronic Lymphocytic Leukemia Display Dysregulated Expression of Immune Checkpoints and Activation Markers. Haematologica (2017) 102(3):562-72. doi: 10.3324/haematol.2016.151100

62. Blanco G, Vardi A, Puiggros A, Gomez-Llonin A, Muro M, Rodriguez-Rivera M, et al. Restricted T Cell Receptor Repertoire in CLL-Like Monoclonal B Cell Lymphocytosis and Early Stage CLL. Oncoimmunology (2018) 7(6):e1432328. doi: 10.1080/2162402X.2018.1432328

63. Mhibik M, Wiestner A, Sun C. Harnessing the Effects of BTKi on T Cells for Effective Immunotherapy Against CLL. Int J Mol Sci (2020) 21(1):68. doi: 10.3390/ijms21010068

64. Niemann CU, Herman SE, Maric I, Gomez-Rodriguez J, Biancotto A, Chang BY, et al. Disruption of In Vivo Chronic Lymphocytic Leukemia TumorMicroenvironment Interactions by Ibrutinib-Findings From an InvestigatorInitiated Phase II Study. Clin Cancer Res (2016) 22(7):1572-82. doi: 10.1158/ 1078-0432.CCR-15-1965

65. Mulder TA, Pena-Perez L, Berglof A, Meinke S, Estupinan HY, Heimersson K, et al. Ibrutinib Has Time-Dependent On- and Off-Target Effects on Plasma Biomarkers and Immune Cells in Chronic Lymphocytic Leukemia. Hemasphere (2021) 5(5):e564. doi: 10.1097/HS9.0000000000000564

66. Long M, Beckwith K, Do P, Mundy BL, Gordon A, Lehman AM, et al Ibrutinib Treatment Improves T Cell Number and Function in CLL Patients. J Clin Invest (2017) 127(8):3052-64. doi: 10.1172/JCI89756

67. Yin Q, Sivina M, Robins H, Yusko E, Vignali M, O'Brien S, et al. Ibrutinib Therapy Increases T Cell Repertoire Diversity in Patients With Chronic Lymphocytic Leukemia. J Immunol (2017) 198(4):1740-7. doi: 10.4049/ jimmunol.1601190

68. Byrd JC, Wierda WG, Schuh A, Devereux S, Chaves JM, Brown JR, et al. Acalabrutinib Monotherapy in Patients With Relapsed/Refractory Chronic Lymphocytic Leukemia: Updated Phase 2 Results. Blood (2020) 135(15):120413. doi: 10.1182/blood.2018884940

69. Dubovsky JA, Beckwith KA, Natarajan G, Woyach JA, Jaglowski S, Zhong Y, et al. Ibrutinib is an Irreversible Molecular Inhibitor of ITK Driving a Th1Selective Pressure in T Lymphocytes. Blood (2013) 122(15):2539-49. doi: 10.1182/blood-2013-06-507947

70. Baptista MJ, Basumallik N, Herman SEM, Cook EM, Ahn IE, Wiestner A, et al. Ibrutinib Increases the Clonality of TCR Repertoire in Patients With Chronic Lymphocytic Leukemia. Blood (2018) 132(Suppl 1):238. doi: 10.1182/ blood-2018-99-109847

71. Estupinan HY, Bouderlique T, He C, Berglof A, Gupta D, Saher O, et al. Novel Mouse Model Resistant to Irreversible BTK Inhibitors: A Tool Identifying New Therapeutic Targets and Side Effects. Blood Adv (2020) 4(11):2439-50. doi: 10.1182/bloodadvances.2019001319

72. Ferrara TJ, Mueller C, Sahu N, Ben-Jebria A, August A. Reduced Airway Hyperresponsiveness and Tracheal Responses During Allergic Asthma in Mice Lacking Tyrosine Kinase Inducible T-Cell Kinase. J Allergy Clin Immunol (2006) 117(4):780-6. doi: 10.1016/j.jaci.2005.12.1330 
73. Podhorecka M, Goracy A, Szymczyk A, Kowal M, Ibanez B, Jankowska-Lecka $\mathrm{O}$, et al. Changes in T-Cell Subpopulations and Cytokine Network During Early Period of Ibrutinib Therapy in Chronic Lymphocytic Leukemia Patients: The Significant Decrease in T Regulatory Cells Number. Oncotarget (2017) 8 (21):34661-9. doi: 10.18632/oncotarget.16148

74. Tsiodras S, Samonis G, Keating MJ, Kontoyiannis DP. Infection and Immunity in Chronic Lymphocytic Leukemia. Mayo Clin Proc (2000) 75 (10):1039-54. doi: 10.4065/75.10.1039

75. Tillman BF, Pauff JM, Satyanarayana G, Talbott M, Warner JL. Systematic Review of Infectious Events With the Bruton Tyrosine Kinase Inhibitor Ibrutinib in the Treatment of Hematologic Malignancies. Eur J Haematol (2018) 100(4):325-34. doi: 10.1111/ejh.13020

76. Rogers KA, Mousa L, Zhao Q, Bhat SA, Byrd JC, El Boghdadly Z, et al. Incidence of Opportunistic Infections During Ibrutinib Treatment for B-Cell Malignancies. Leukemia (2019) 33(10):2527-30. doi: 10.1038/s41375-019-0481-1

77. Nadali G, Marchesini G, Facchinelli D, Farina F, Tisi MD, Lessi L, et al. Infections in Patients With Lymphoproliferative Diseases Treated With Target Therapy. Italian Multicentric Retrospective Study Seifem 2017, Blood (2018) 132(Suppl 1):4164. doi: 10.1182/blood-2018-99-111518

78. Varughese T, Taur Y, Cohen N, Palomba ML, Seo SK, Hohl TM, et al. Serious Infections in Patients Receiving Ibrutinib for Treatment of Lymphoid Cancer. Clin Infect Dis (2018) 67(5):687-92. doi: 10.1093/cid/ciy175

79. Burger JA, Barr PM, Robak T, Owen C, Ghia P, Tedeschi A, et al. Long-Term Efficacy and Safety of First-Line Ibrutinib Treatment for Patients With CLL/ SLL: 5 Years of Follow-Up From the Phase 3 RESONATE-2 Study. Leukemia (2020) 34(3):787-98. doi: 10.1038/s41375-019-0602-x

80. Svensson T, Kattstrom M, Hammarlund Y, Roth D, Andersson PO, Svensson $M$, et al. Pneumococcal Conjugate Vaccine Triggers a Better Immune Response Than Pneumococcal Polysaccharide Vaccine in Patients With Chronic Lymphocytic Leukemia A Randomized Study by the Swedish CLL Group. Vaccine (2018) 36(25):3701-7. doi: 10.1016/j.vaccine.2018.05.012

81. de Lavallade H, Garland P, Sekine T, Hoschler K, Marin D, Stringaris K, et al. Repeated Vaccination is Required to Optimize Seroprotection Against H1N1 in the Immunocompromised Host. Haematologica (2011) 96(2):307-14. doi: 10.3324/haematol.2010.032664

82. Douglas AP, Trubiano JA, Barr I, Leung V, Slavin MA, Tam CS. Ibrutinib may Impair Serological Responses to Influenza Vaccination. Haematologica (2017) 102(10):e397-e9. doi: 10.3324/haematol.2017.164285

83. Sun C, Gao J, Couzens L, Tian X, Farooqui MZ, Eichelberger MC, et al. Seasonal Influenza Vaccination in Patients With Chronic Lymphocytic Leukemia Treated With Ibrutinib. JAMA Oncol (2016) 2(12):1656-7. doi: 10.1001/jamaoncol.2016.2437

84. Pleyer C, Ali MA, Cohen JI, Tian X, Soto S, Ahn IE, et al. Effect of Bruton Tyrosine Kinase Inhibitor on Efficacy of Adjuvanted Recombinant Hepatitis B and Zoster Vaccines. Blood (2021) 137(2):185-9. doi: 10.1182/ blood.2020008758

85. Zent CS, Brady MT, Delage C, Strawderman M, Laniewski N, Contant PN, et al. Short Term Results of Vaccination With Adjuvanted Recombinant Varicella Zoster Glycoprotein E During Initial BTK Inhibitor Therapy for CLL or Lymphoplasmacytic Lymphoma. Leukemia (2020) 1788-91. doi: 10.1038/ s41375-020-01074-4

86. Muchtar E, Koehler A, Johnson MJ, Rabe KG, Ding W, Call TG, et al. Immunogenicity of a Recombinant Herpes Zoster Vaccine in Patients With Chronic Lymphocytic Leukemia. Blood (2020) 136(Suppl 1):49-50. doi: 10.1182/blood-2020-140338

87. Mauro FR, Giannarelli D, Galluzzo CM, Vitale C, Visentin A, Riemma C, et al. Response to the Conjugate Pneumococcal Vaccine (PCV13) in Patients With Chronic Lymphocytic Leukemia (CLL). Leukemia (2020) 737-46. doi: 10.1038/s41375-020-0884-Z

88. Andrick B, Alwhaibi A, DeRemer DL, Quershi S, Khan R, Bryan LJ, et al. Lack of Adequate Pneumococcal Vaccination Response in Chronic Lymphocytic Leukaemia Patients Receiving Ibrutinib. Br J Haematol (2018) 182(5):712-4. doi: 10.1111/bjh.14855

89. Scarfo L, Chatzikonstantinou T, Rigolin GM, Quaresmini G, Motta M, Vitale C, et al. COVID-19 Severity and Mortality in Patients With Chronic Lymphocytic Leukemia: A Joint Study by ERIC, the European Research Initiative on CLL, and CLL Campus. Leukemia (2020) 34(9):2354-63. doi: 10.1038/s41375-020-0959-x

90. Mato AR, Roeker LE, Lamanna N, Allan JN, Leslie L, Pagel JM, et al. Outcomes of COVID-19 in Patients With CLL: A Multicenter International Experience. Blood (2020) 136(10):1134-43. doi: 10.1182/blood.2020006965

91. Liang C, Tian D, Ren X, Ding S, Jia M, Xin M, et al. The Development of Bruton's Tyrosine Kinase (BTK) Inhibitors From 2012 to 2017: A Mini-Review. Eur J Med Chem (2018) 151:315-26. doi: 10.1016/j.ejmech.2018.03.062

Conflict of Interest: MP: Takeda, research support. Beigene, research support. AÖ: Beigene, research support. Astra Zeneca: research support. Gilead: research support. Loxo Oncology: research support.

The remaining authors declare that the research was conducted in the absence of any commercial or financial relationships that could be construed as a potential conflict of interest.

Copyright (c) 2021 Palma, Mulder and Österborg. This is an open-access article distributed under the terms of the Creative Commons Attribution License (CC BY). The use, distribution or reproduction in other forums is permitted, provided the original author(s) and the copyright owner(s) are credited and that the original publication in this journal is cited, in accordance with accepted academic practice. No use, distribution or reproduction is permitted which does not comply with these terms. 